
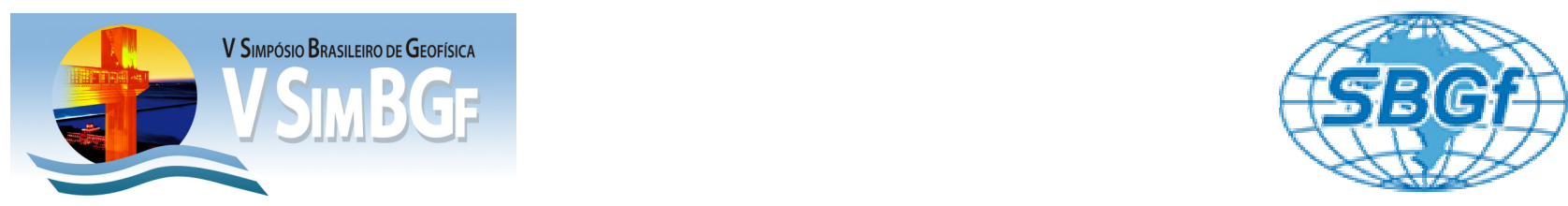

\title{
Processamento de Dados Sísmicos Reais da Bacia do Amazonas Utilizando as Migrações de Kirchhoff Pós e Pré-empilhamento em Tempo
}

\author{
Daniel Galvão Ferreira (UFPA), João Carlos Ribeiro Cruz (') \\ Copyright 2012, SBGf - Sociedade Brasileira de Geofísica \\ Este texto foi preparado para a apresentação no V Simpósio Brasileiro de Geofísica, \\ Salvador, 27 a 29 de novembro de 2012. Seu conteúdo foi revisado pelo Comitê \\ Técnico do V SimBGf, mas não necessariamente representa a opinião da SBGf ou de \\ seus associados. É proibida a reprodução total ou parcial deste material para \\ propósitos comerciais sem prévia autorização da SBGt.
}

\section{Resumo}

O presente trabalho apresenta os resultados do processamento de dados sísmicos das linhas 0204-RL0053, 0204-RL-0057 e 0204-RL-0058 da Bacia do Amazonas. Dentre as diversas dificuldades na exploração de petróleo nessa região, as soleiras de diabásio existentes nessa bacia, apesar de terem executado um importantíssimo papel durante o processo de maturação da matéria orgânica, dificultam a exploração sísmica por causarem espalhamento da onda sísmica e gerarem reflexões múltiplas, aumentado o risco exploratório pela formação de falsas estruturas devido aos efeitos de pull-up e pull-down. Neste contexto, o presente trabalho tem como objetivo melhorar 0 imageamento sísmico das seções processadas e assim favorecer uma melhor interpretação dos refletores sísmicos. Os métodos aplicados são o empilhamento CMP e as migrações de Kirchhoff Pós e Préempilhamento em tempo.

\section{Introdução}

A Bacia intracratônica do Amazonas como um todo, Alto Amazonas (Solimões), Médio e Baixo Amazonas (Amazonas), está inserida no contexto da floresta Amazônica e implantada sobre o Cráton Amazônico de idade e evolução pré-Ciclo Brasiliano. Localizada no interior da Plataforma Sul-Americana, a "Bacia do Amazonas", atualmente, corresponde às antigas bacias do Médio e Baixo Amazonas, enquanto que a denominação "Bacia do Solimões" corresponde à Bacia do Alto Amazonas (CAPUTO 1984). Em estudos mais antigos, o nome "Bacia do Solimões" se aplicava à cobertura cenozóica do oeste da Amazônia, mas Caputo (1984) sugeriu a substituição do nome Alto Amazonas por Solimões, devido a esta apresentar uma história tectono-sedimentar diferenciada da Bacia do Amazonas.

Eventos tectono-termais, caracterizados por pulsos magmáticos que atingiram praticamente todas as bacias paleozóicas brasileiras, foram os responsáveis pela injeção de material magmático no interior da bacia do Amazonas dando origem as soleiras de diabásio. Apesar dessas soleiras que se encontram intrudidas nas rochas paleozóicas da bacia do Amazonas terem exercido um papel importante no processo de maturação da matéria orgânica, sob o ponto de vista exploratório, a ocorrência de rochas magmáticas nas porções internas de bacias sedimentares são uma problemática para a exploração geofísica por se tratarem de rochas que dificultam a penetração das ondas sísmicas (EIRAS e WANDERLEY FILHO, 2002). Com o propósito de melhor entender e suprimir os efeitos negativos na qualidade das imagens sísmicas da Bacia do Amazonas, o presente trabalho tem como objetivo principal produzir imagens sísmicas de melhor qualidade por meio do reprocessamento de linhas sísmicas utilizando técnicas convencionais de tratamento de dados sísmicos como a migração pós-empilhamento em tempo e técnicas modernas empregadas na atualidade pela indústria como a migração préempilhamento em tempo (PreSTM).

O método de migração escolhido para integrar o presente trabalho foi a migração de Kirchhoff no domínio do tempo. Esse método baseia-se na soma, ou espalhamento ponderado, de amplitudes ao longo de curvas de tempo de trânsito de difração, ou curvas isócronas. A migração Kirchhoff foi utilizada tanto nas seções migradas com a técnica pós-empilhamento, quanto nas seções migradas com a técnica préempilhamento.

\section{Metodologia}

As linhas sísmicas 0204-RL-0053, 0204-RL-0057 e 0204-RL-0058, mostradas na Figura 1, fazem parte de um conjunto de dados adquiridos da Agência Nacional do Petróleo, Gás Natural e Biocombustíveis (ANP) pelo Instituto de Geociências da Universidade Federal do Pará (IG-UFPA) para fins de desenvolvimento acadêmico.

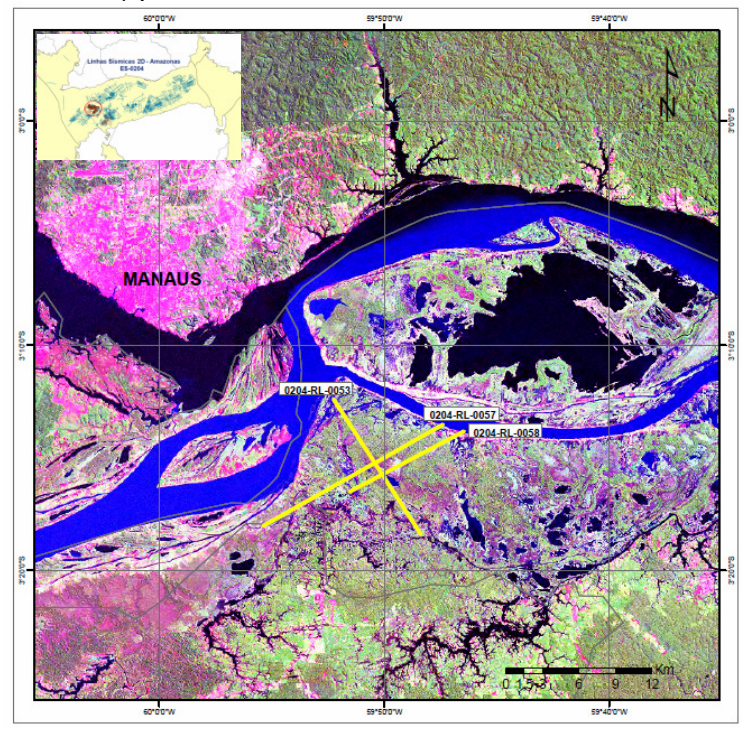

Figura 1 - Mapa de localização das linhas sísmicas 0204- $R L$ 0053, 0204-RL-0057 e 0204-RL-0058 destacadas em amarelo. 
Toda a etapa de pré-processamento dos dados sísmicos, análise de velocidades e migração de Kirchhoff pós e pré-empilhamento em tempo foi realizada com 0 aplicativo comercial ProMAX®, versão 2003.19.1.1, da Landmark Graphics Corporation, empresa da Halliburton Ltda. Também foi utilizado o programa ArcGIS, versão 9.2, para a localização e o georreferenciamento das três linhas usadas neste trabalho.

Como já foi citado anteriormente as soleiras de diabásio presentes na Bacia do Amazonas e em todas as bacias paleozóicas brasileiras, foram geradas pelo Evento Penatecaua no Jurotriássico durante a abertura do Atlântico Norte (ISSLER et al., 1974) e atuaram como fonte extra de calor para o processo de transformação da matéria orgânica em óleo e gás, assim como no craqueamento de óleo na bacia. Por outro lado, essas soleiras de diabásio são um problema para geofísica de exploração. A problemática está na dificuldade em processar dados sísmicos de baixa qualidade proveniente de área com feições geológicas complexas associadas à ocorrência de rochas magmáticas, como as da bacia do Amazonas. Esse obstáculo surge do fato de que as soleiras de diabásio podem deteriorar a qualidade das seções sísmicas, por causarem a perda do sinal, a geração de múltiplas e o espalhamento do sinal, prejudicando assim, a interpretação dos dados pela formação de falsas estruturas (EIRAS; WANDERLEY FILHO, 2002).

\section{Migração de Kirchhoff}

A migração de dados sísmicos tem como objetivo posicionar corretamente os refletores sísmicos em subsuperfície. Este processo busca corrigir os eventos das seções sísmicas, deslocando as reflexões primárias para suas verdadeiras posições espaciais e colapsando as difrações, produzindo assim, uma imagem sísmica que possibilite uma melhor interpretação dos dados sísmicos, ou seja, proporciona maior similaridade entre a seção sísmica migrada e a seção geológica.

Este método opera em dois aspectos distintos do dado sísmico, tempo de trânsito e amplitude. No tempo de trânsito, que carrega informações da estrutura geológica do meio e de suas velocidades, a migração age de forma a reposicionar as reflexões tanto em suas coordenadas de superfície quanto nas coordenadas de tempo. $\mathrm{Na}$ amplitude, que traz informações sobre a litologia e fluidos na subsuperfície, especificamente o contraste das propriedades das camadas que definem a interface de reflexão, a migração atua de modo a corrigir efeitos de propagação da onda e fornecer valores de amplitude que, relativamente, representam o conjunto das propriedades petrofísicas do meio.

A migração utilizada no presente trabalho, no caso migração de Kirchhoff, resulta do antigo método estatístico do empilhamento de difrações, o qual trabalha empilhando as amplitudes dos dados de entrada $(x, t)$ ao longo de uma hipérbole de difrações, cuja curvatura é governada por uma função velocidade. O método tornouse consistente quando SCHNEIDER (1978) apresentou uma solução exata para equação da onda acústica via integral de Kirchhoff, ou seja, o simples somatório de amplitudes foi convertido em uma integral que implica correções de amplitude e fase antes do somatório dos dados, transformando 0 método estatístico em determinístico. Pela eficiência e flexibilidade de aplicação, esse método determinístico de Kirchhoff mostrou-se revolucionário para os métodos sísmicos em especial à migração sísmica.

A migração de Kirchhoff pode ser classificada quanto ao tipo de dados de entrada, os quais podem ser: a) seções empilhadas simulando dados em afastamento nulo ou b) painéis de dados pré-empilhados organizados em tiros, receptores ou afastamentos tiros-receptores comum. No primeiro caso, a aplicação de um algoritmo de migração aos dados empilhados é chamada de migração pósempilhamento. Já a migração de dados, organizados em painéis de tiros, receptores ou afastamentos tirosreceptores comuns, é denominada migração préempilhamento (OGORODNIK, 2007).

\section{Integral de Kirchhoff}

A migração de Kirchhoff considera uma reflexão primária como sendo formada pelo envelope de todas as curvas de difrações oriundas de pontos difratores posionados sobre o respectivo refletor. Realizando o empilhamento de amplitudes e com base no Princípio de Huygens, a migração de Kirchhoff produz valores de amplitude onde o ponto em estudo está sobre um refletor (Figura 2).

Deste modo, não há necessidade de um prévio conhecimento das reflexões, apenas deve-se ter um campo de velocidade que represente razoavelmente a distribuição espacial das velocidades na subsuperfície para o cálculo das curvas de difração.

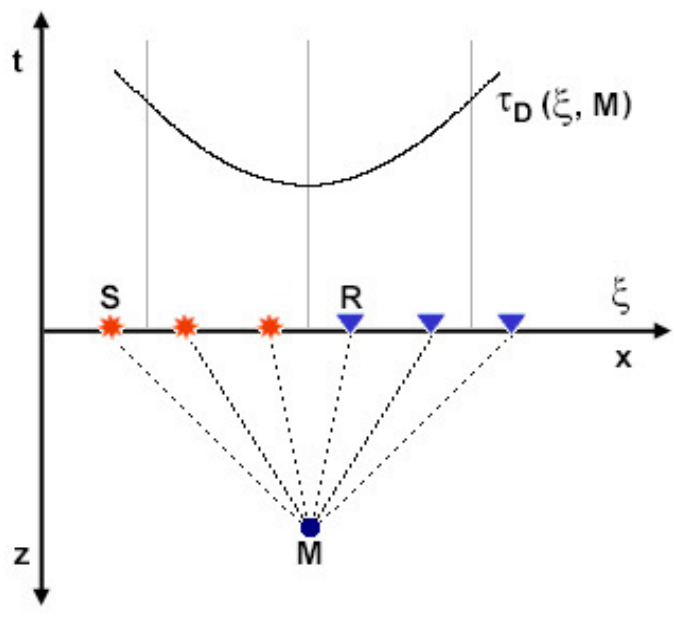

Figura 2 - Diagrama esquemático de construção da curva de tempos de trânsito de difração. Fonte: Adaptado de BIONDI (2006).

Assim, dado um ponto $M$, de coordenadas ( $\mathrm{x}, \mathrm{z})$, e uma determinada configuração dos dados sísmicos de entrada, descrita pelo parâmetro de configuração $\xi$, a migração de Kirchhoff pode ser expressa pela integral (SCHLEICHER et al, 1993):

$$
v(M)=\int_{a} w(\xi, M) D\left[U\left(\xi_{n} t=\tau_{w}\left(\xi_{1}, M\right)\right] d \xi\right.
$$


onde $V(M)$ é a amplitude migrada para um ponto $M$ da seção de saída; $\Omega$, corresponde ao domínio de integração na superfície; $W(\xi, M)$ ao fator de ponderação e $D$ ao operador de correção de mudança de fase decorrente do processo de migração. Os traços da seção de entrada $U(\xi, t)$ equivalentes ao dado registrado no receptor, são descritos pelo parâmetro $\xi$.

A equação (1) expressa que para cada ponto $M$ da seção de saída, a integral é avaliada nos valores de amplitude da seção de entrada, ao longo da trajetória de empilhamento dos eventos de difração $\boldsymbol{\tau}_{D}\left(\boldsymbol{\xi}_{*} \boldsymbol{M}\right)$ dentro da abertura de migração $\Omega$ (região de integração) e ponderada pela função peso $W(\xi, M)$, usada para retirar das amplitudes resultantes o efeito de espalhamento geométrico. Repetindo esta operação para todos os pontos da seção de saída, obtemos a seção migrada.

\section{Migração de Kirchhoff Pós-Empilhamento}

A migração pós-empilhamento é geralmente empregada nas seções empilhadas de afastamento nulo. Nesta configuração, fonte e receptor estão localizados na mesma posição espacial e, portanto:

$$
\xi=x_{x}=x_{n}
$$

onde $\boldsymbol{x}_{s}$ e $\boldsymbol{x}_{\boldsymbol{F}}$ são as coordenadas de fonte e receptor, respectivamente. Então, considerando a configuração de afastamento nulo, a fórmula geral da integral de Kirchhoff (5.1) se torna:

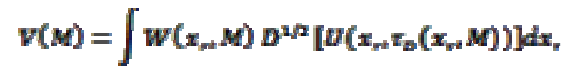

A migração em tempo coloca a amplitude migrada no ápice da hipérbole, correspondente ao tempo de trânsito do raio vertical (raio imagem) associado ao ponto de difração; ao passo que a migração em profundidade coloca no ponto difração.

A migração pós-empilhamento em tempo define o ponto geométrico de uma possível difração, baseado no tempo de reflexão, no intervalo entre traços e na velocidade média até a amostra considerada. Com isso, o operador de migração realiza o somatório de todas as amostras registradas intersectadas pela hipérbole de difração, resultando no valor migrado no ponto considerado. Repetindo este processo para todas as amostras de todos os traços, obtêm-se a seção migrada final.

\section{Migração de Kirchhoff Pré-Empilhamento}

A migração pré-empilhamento é a designação dada ao método de migração aplicada em seções pré-empilhadas quando a mesma está baseada na configuração de afastamento comum, ou seja, a migração préempilhamento pode ser considerada como um desenvolvimento da técnica pós-empilhamento considerando o afastamento não-nulo. Para tal, cada traço sísmico de uma seção Common offset é individualizado pelo valor da coordenada de ponto médio $\left(x_{m}\right)$.

Logo, considerando está configuração, matematicamente o processo de migração Kirchhoff é representado pela seguinte integral:

$$
V(M)=\int W\left(x_{m,}, M\right) D^{2} / z\left[V\left(x_{m^{\prime}}, t=x_{p}\left(x_{m,}, M\right)\right] d x_{m}\right.
$$

sendo $W$ a função peso ponderada as amplitudes de migração, $x_{m} \circ$ ponto médio, $M \circ$ ponto imagem, $D$ a derivada de meio tempo aplicado aos dados de entrada para restaurar a forma da wavelet.

Neste trabalho, a migração Kirchhoff pré-empilhamento considera meios homogêneos e com velocidade constante, em que os tempos de difrações são calculados por:

$$
x_{v}\left(x_{m}, M\right)=\frac{1}{v} \sqrt{\left(x_{a}-x_{m}+h\right)^{2}+m^{2}}+\sqrt{\left(x_{0}-x_{m}-h\right)^{2}+p^{2}}
$$

sendo $x_{0}$ a projeção horizontal das coordenadas do ponto imagem $\boldsymbol{M}$.

Deste modo, a curva de tempos de difração para o ponto $\boldsymbol{M}$ em uma seção Common offset é traçada variando-se as coordenadas $\boldsymbol{x}_{m}$ dos pontos médios. Sobre esta curva são reunidas as amostras, que após serem multiplicadas pelo peso $W$ são somadas e o resultado atribuído ao ponto $M$ da seção de saída.

Supondo-se que se tenha uma amostragem contínua tanto em $\boldsymbol{h}$ quanto em $\boldsymbol{x}_{\boldsymbol{m}}$, pode-se calcular o tempo de difração para um ponto $M$ em subsuperfície gerando assim a pirâmide de tempos de difração (Figura 3) ou pirâmide de Quéops (CLAERBOUT, 1985).

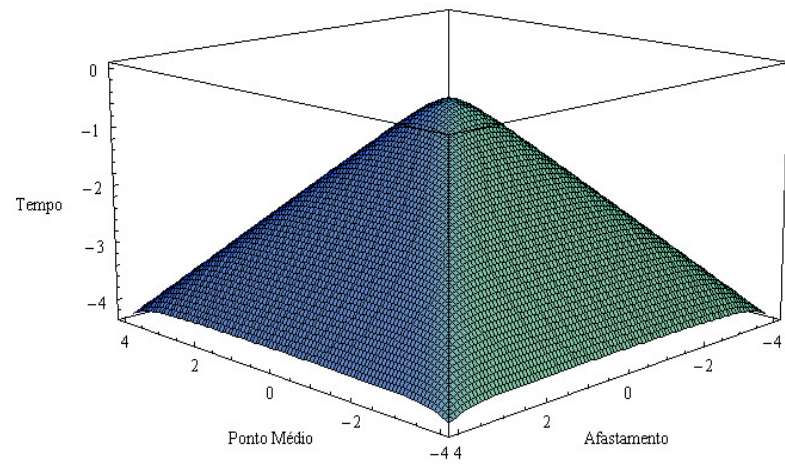

Figura 3 - Pirâmide de tempos de difração formada pelas trajetórias de empilhamento para uma seção Common offset. Fonte: Adaptado de Biondi (2006).

\section{Resultados}

As seções migradas finais pós e pré-empilhamento em tempo foram organizadas visando uma melhor comparação entre os dois processos, de modo que as Figuras 4 e 5 representam as seções migradas pós e préempilhamento da linha 0204-0053, respectivamente. As Figuras 6 e 7 representam as seções migradas pós e préempilhamento da linha 0204-0057, respectivamente e, finalmente, as Figuras 8 e 9 são referentes as seções 
migradas pós e pré-empilhamento da linha 0204-0058, respectivamente.

As duas seções sísmicas, pós e pré-empilhamento, correspondentes à linha 0204-RL-0053, Figuras 4 e 5, respectivamente, apresentam boa resolução $e$ continuidade lateral dos refletores, principalmente no intervalo de 0.4 a $1 \mathrm{~s}$. Não obstante, ponderou-se que a seção migrada pré-empilhamento alcançou maior continuidade lateral dos eventos de reflexões profundos, assim como melhor definição dos refletores localizados nas partes rasas. Esta melhora na seção da referida linha sísmica pode ser observada, principalmente, entre os CDPs 250 a 290 e 342 a 367, nos intervalos de 2.4 a 2.6 $\mathrm{s}$ e 0.6 a $0.8 \mathrm{~s}$, respectivamente, onde os refletores apresentam-se com melhor resolução na seção migrada com a técnica pré-empilhamento.

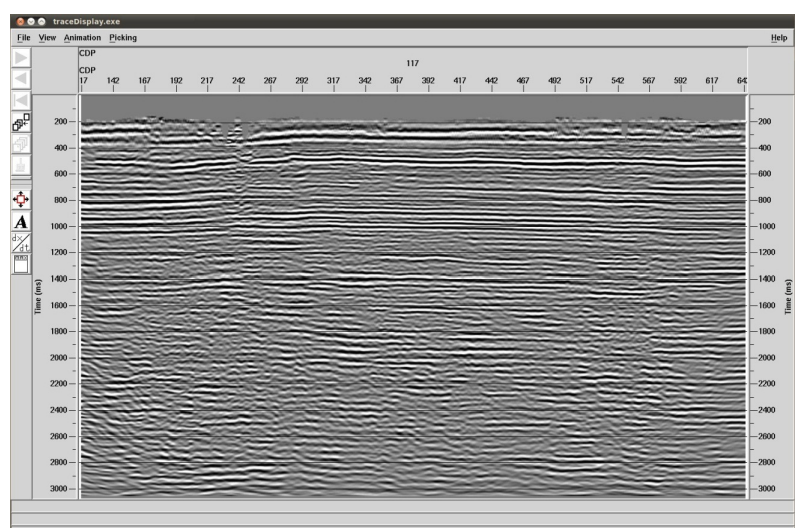

Figura 4 - Seção migrada com a técnica pós-empilhamento em tempo da linha 0204-RL-0053.

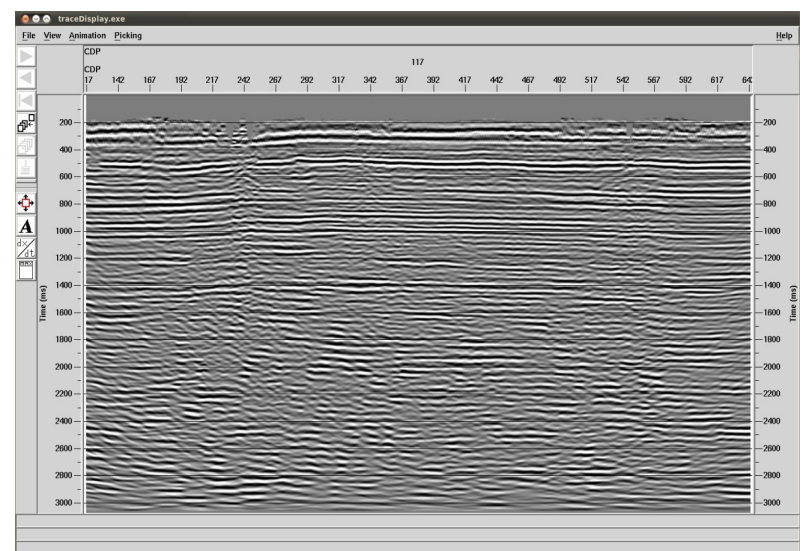

Figura 5 - Seção migrada com a técnica pré-empilhamento em tempo da linha 0204-RL-0053.

A grande quantidade de "tiros" perdidos na fase de aquisição (faixa sem reflexão entre os CDPs 320 e 360) e a baixa qualidade dos dados sísmicos da linha 0204-RL0057, devido à baixa razão sinal-ruído dos traços e a baixa cobertura, comprometeram tanto a seção migrada pós-empilhamento como a seção migrada préempilhamento, Figuras 6 e 7, respectivamente.

$\mathrm{Na}$ seção migrada com a técnica pós-empilhamento observa-se descontinuidades laterais dos eventos de reflexão em várias partes da seção e má resolução dos refletores abaixo de $1.6 \mathrm{~s}$. Apesar dos problemas da baixa razão sinal-ruído dos traços e a baixa cobertura que comprometem os processos automáticos de coerência, a seção migrada pré-empilhamento apresentou uma melhora na definição e continuidade lateral dos eventos de reflexão profundos, abaixo de 1.6 s. Essa melhora pode ser observada, entre os CDPs 380 a 680 , nos intervalos de 1.8 a $2.2 \mathrm{~s}$.

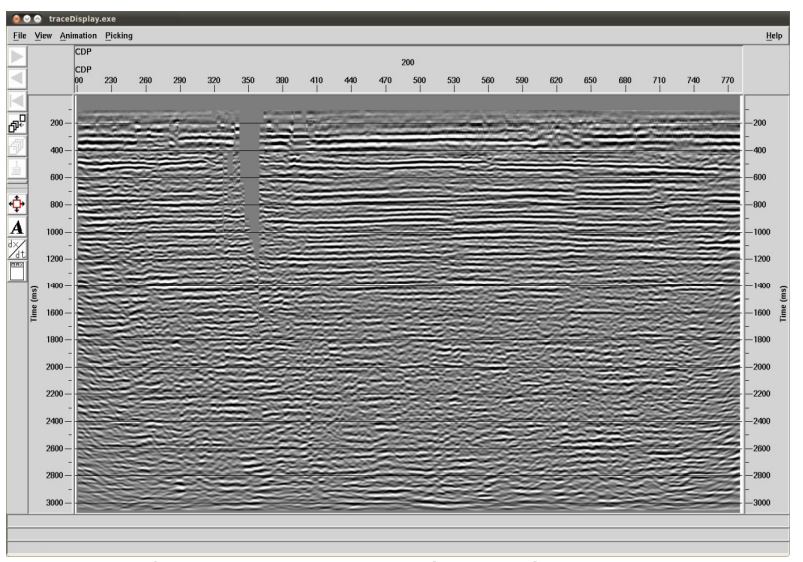

Figura 6 - Seção migrada com a técnica pós-empilhamento em tempo da linha 0204-RL-0057.

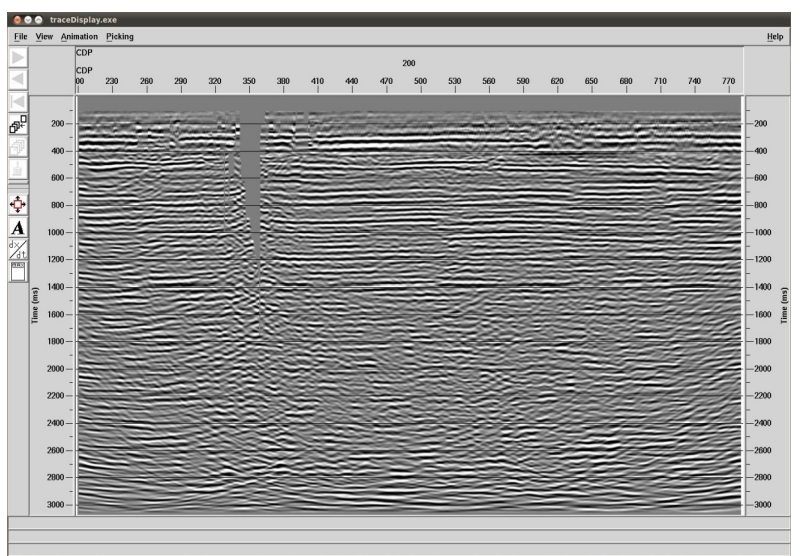

Figura 7 - Seção migrada com a técnica pré-empilhamento em tempo da linha 0204-RL-0057.

Assim como nas seções da linha 0204-RL-0053, ambas as seções correspondentes à linha 0204-RL-0058, seção migrada pós e pré-empilhamento, Figuras 8 e 9 , respectivamente, apresentaram continuidade lateral dos eventos de reflexão e boa resolução. Mas, observou-se que a seção migrada com a técnica pré-empilhamento em tempo obteve melhor definição e maior continuidade lateral dos eventos de reflexão mais profundos, principalmente no intervalo de 1.6 a $2.4 \mathrm{~s}$. Esta melhora também pode ser observada na parte mais rasa da seção, entre os CDPs 581 e 701 no intervalo de 1.2 a 1.3 s. 


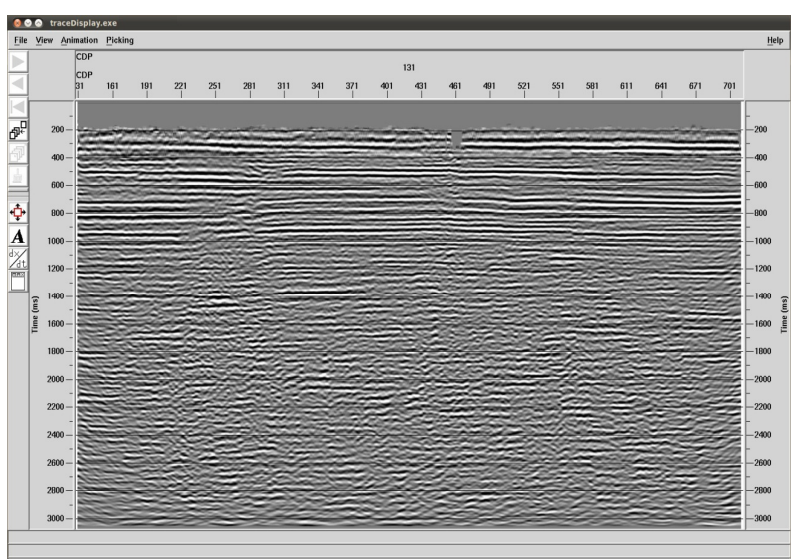

Figura 8 - Seção migrada com a técnica pós-empilhamento em tempo da linha 0204-RL-0058.

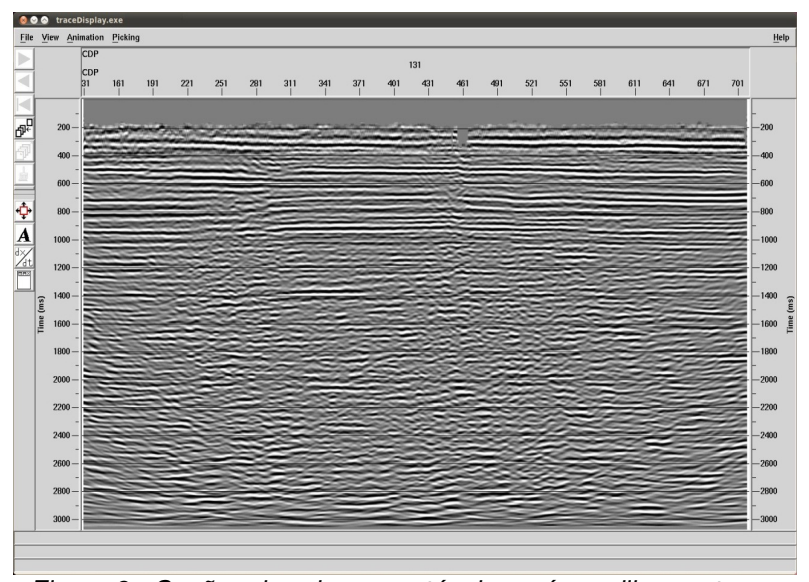

Figura 9 - Seção migrada com a técnica pré-empilhamento em tempo da linha 0204-RL-0058.

\section{Conclusões}

Apesar da baixa qualidade e da baixa cobertura dos dados sísmicos utilizados no presente trabalho, a fase de pré-processamento (geometria, edição, correção estática, deconvolução e filtragem) foi satisfatória, o que pode ser comprovado pelos bons resultados obtidos tanto na migração de Kirchhoff pós-empilhamento quanto na migração de Kirchhoff pré-empilhamento em tempo. No entanto, os resultados obtidos com a técnica préempilhamento se mostraram superiores comparados com os resultados obtidos com a técnica de migração pósempilhamento, apesar dos resultados obtidos com está última técnica também, ter se mostrado bastante eficiente na reconstrução da imagem dos refletores.

A qualidade superior das seções migradas préempilhamento, comparadas as seções migradas com a técnica pós-empilhamento, pode estar relacionado aos bons e precisos modelos de velocidades obtidos no processamento, apesar das mudanças laterais de velocidade e da baixa qualidade dos dados sísmicos. Esse resultado, aparentemente comum, não é habitual para dados sísmicos terrestres, onde se torna muito complexo e oneroso obter com precisão um modelo com as informações sobre a distribuição das velocidades em subsuperfície.

\section{Agradecimentos}

O primeiro autor agradece ao Convênio UFPA/ANP/MCT/PRH-06, pelo apoio financeiro a qualidade de bolsa de estudo.

À Universidade Federal do Pará, pelos equipamentos e espaços cedidos.

\section{Referências}

BIONDI, B. L. 3-D Seismic imaging. Tulsa: Society of Exploration Geophysics, 2006.

CAPUTO, M. V. Stratigraphy, tectonics, paleoclimatology and paleogeography of Northern Basins of Brazil. 1984. 583f. Tese (Doutorado), University of California, Santa Barbara. 1984.

CLAERBOUT, J. F. Imaging the earth's interior. Oxford: Blackwell Scientific Publications. 1985. 398 p.

EIRAS, J. F.; WANDERLEY FILHO, J.R. Ocorrências de petróleo relacionadas a rochas magmáticas fanerozóicas. In: SIMPÓSIO SOBRE VULCANISMO E AMBIENTES ASSOCIADOS, 2., 2002, Belém. Boletim de resumos e roteiro de excursão. Belém: Núcleo PRONEX do Centro de Geociências da UFPA, 2002. p.54.

ISSLER, R. S. et al. Geologia da Folha SA.22 Belém. In: BRASIL. DEPARTAMENTO NACIONAL DE PRODUÇÃO MINERAL. Projeto RADAM. Folha SA.22 Belém. Rio de Janeiro: DNPM, 1974, v.5, p.160.

OGORODNIK, F. S. Processamento de dados sísmicos da Bacia do Tacutu utilizando as migrações de Kirchhoff Pós e Pré-empilhamento em tempo. 2007. 70f. Trabalho de conclusão de curso (graduação). Universidade Federal do Pará, Instituto de Geociências, Faculdade de Geofísica, Belém, 2007.

SCHLEICHER, J., TYGEL, M., HUBRAL, P. 3-D trueamplitude finite-offset migration. Geophysics, v.58, n.8, p.1112-1126, ago., 1993.

SCHNEIDER, W. A. Integral formulation for migration in two and three dimensions. Geophysics, v. 43, n. 1, p. 49-76, 1978. 